\title{
Establishing and Developing Critical Thinking in the Courses of Educational Institutions
}

\author{
Ani Manukyan \\ Armenian State Pedagogical University
}

\begin{abstract}
$\mathrm{C}^{\mathrm{n}}$ ritical thinking is the ability to apply reasoning and logic to unfamiliar ideas, opinions and situations. It helps to function effectively in the changing world of the $21^{\text {st }}$ century. Thinking critically involves seeing things in an open-minded way. This important skill allows people to look past their own views of the world and to adopt a more aware way of viewing the world.The ability to think critically is essential, especially in a globally-minded world. Critical thinking is the process of analyzing, interpreting or evaluating both the tangible and intangible world. The ability to be open-minded is a large part of thinking critically, and allows a person not only to seek out all possible answers to a problem, but also to accept an answer that is different from what was originally thought. A person must not always assume that his way of approaching a situation is always the best, or even right.

Critical thinking has not ever been an objective in education in Armenia. In many European countries school system, the syllabus offers critical thinking as a subject which 16-18-year-olds can take. The exam tests candidates not on particular information they have learned during the course, but on their ability to think critically about, and analyze arguments on their deductive or inductive validity. The subject is very challenging and extremely useful for degree courses in politics, philosophy and history providing the skills required for critical analysis. As compared with the Western countries, which have more practice in the development of critical thinking, the situation in Armenia is completely different. Learners are not encouraged to improve themselves as thinkers. Emphasis is put on information transmission. However, accent on memory, practice, rote learning and little focus on higher-order thinking has a negative effect on the quality of teaching/learning. The majority of school leavers, who are being fed with finished statements, are not able to think rationally: they can't consider the problem from different perspectives, back arguments with evidence and reference to consequences, formulate their own conclusions, defend their assertions with reasons. Actually, parents, and the professional public are greatly concerned that young people at secondary schools fail to acquire the necessary skills and knowledge to meet the reallife challenges and benefit from a world which offers enormous opportunities. Employers are also very critical about young people's readiness to join the labor market.They consider that many of the employees do not possess the knowledge and skills to be competitive in a rapidly changing world. This confirms that traditional educational strategies based on passive learner role and work with information by learning it by heart fail to meet the changed society needs and, therefore, have to be replaced by problem based, meaningful activities where a learner is placed in the center of educational processes. The curricula of educational institutions should provide a special system to develop the ability to think critically. The importance to develop critical thinking in con-
\end{abstract}


temporary educational systems should also be outlined. Critical thinking is considered to bean essential constituent of the academic world generally because this is the main way that knowledge is added to a field. Critical thinking is a desirable skill in all aspects of university work because it allows knowledge andskills to develop and evolve. It is necessary in students' reading, note making, assignment writing, tutorial presentations and professional practice. Therefore, under present circumstances, the development of critical thinking becomes a promising strategy helping to increase learning effectiveness while teaching any subject matter.

Thus, only conscious learning and reasonably active teaching with the focus on critical thinking skills might help a learner achieve positive results in any field, foreign languages included. The problem is that the basic intellectual standards essential to critical thinking are not typically taught in schools. Therefore young people at the university frequently display poor reasoning and problem-solving skills.

Creative thinking should be incorporated into the development of critical thinking through collaborative learning activities. Almost all of the thinking which we undertake contains some critical and creative aspects. Creative thinking is generally considered to be involved with the creation or generation of ideas, processes, and experiences, whereas critical thinking is concerned with their evaluation. Therefore critical and creative thinking, as interrelated and complementary aspects of good thinking processes, should be developed together (Chubinski 1996:64-73; Klenz 1987:36-51).

Collaborative learning structures can also contribute to the development of critical thinking if the right strategy is chosen. It is determined that a correct strategy while developing critical thinking should include:

- interpersonal contact: to put different learners together,

- creating mutual interdependence and common aim: there should not be too strong competition between team members. They have to take care to create conditions for interdependence and not for too individual work, that is, a good group climate should be realized,

- equal status among members: a different role exists only in the leader status, but the leader of a team should have only a limited power. He/she should be more a coordinator than a 'boss',

- a teacher should perform the role of a consultant offering the students a strong support to seek imaginative, constructive, ethical solutions to problems (Chaffee 1985:87-95).

Critical thinking assignments don't need to cover alloutcomes at one time but they can vary throughout the course. It is necessary to modify old and create new assignments that use critical thinking criteria.

Another aspect of criticalthinking is the ability to think rationally. Rationality requires analyzing all known evidence, not leaving something out because it doesn't fit your accepted view. Rationality does not rely on emotions for evidence, but instead relies on hard proven fact. Critical thinking also requires a non-judgmental and honest approach to reasoning. Being honest requires noting and acknowledging personal goals, motives, and emotions that might color opinions or thought processes. 
S. Ferrett advances the following characteristics of critical thinker:

1. Asks pertinent questions.

2. Assesses statements and arguments.

3. Is able to admit a lack of understanding or information.

4. Has a sense of curiosity.

5. Is interested in finding new solutions.

6. Is able to clearly define a set of criteria for analysing ideas.

7. Is willing to examine beliefs, assumptions, and opinions, and weigh them against facts.

8. Listens carefully to others and is able to give feedback.

9. Sees that critical thinking is a lifelong process of self-assessment.

10. Looks for evidence to support assumptions and beliefs.

11. Is able to adjust opinions when new facts are found.

12. Looks for proof.

13. Examines problems closely.

14. Is able to reject information that is incorrect or irrelevant (Ferrett 1997:34-76).

The variety of ways in which critical thinking is conceptualized gives rise to different interpretations as far as its key elements (abilities, knowledge, skills, processes, values, attitudes) are concerned. While the knowledge base required for critical reflection varies from subject to subject, the underlying values and attitudes remain constant across school subjects. Although skills and processes are somewhat dependent upon specific subject matter, the same values and attitudes are required in all subjects for their execution. Therefore it is very important to evaluate the above mentioned elements while incorporating critical thinking into the teaching.

Critical thinking is not only a matter of accumulating information. A person with a good memory and who knows a lot of facts is not necessarily good at critical thinking. A critical thinker is able to deduce consequences from what he knows, and he knows how to make use of information to solve problems, and to seek relevant sources of information to inform himself.

Critical thinking should not be confused with being argumentative or being critical of other people. Although critical thinking skills can be used in exposing fallacies and bad reasoning, it can also play an important role in cooperative reasoning and constructive tasks. Critical thinking can help us acquire knowledge, improve our theories, and strengthen arguments.

Good critical thinking might be seen as the foundation of science and a liberal democratic society. Science requires the critical use of reason in experimentation and theory confirmation. The proper functioning of a liberal democracy requires citizens who can think critically about social issues to inform their judgments about proper governance and to overcome biases and prejudices.

The key to critical thinking is to develop an impersonal approach which looks at arguments and facts and which lays aside personal views and feelings. This is because academic discourse is based on key principles which are described as follows by Northedge: 
- Debate: arguing different points of view.

- Scholarship: awareness of what else has been written, and citing it correctly.

- Argument: developing points in a logical sequence which leads to a conclusion.

- Criticism: looking at strengths and weaknesses.

- Evidence: ensuring that the argument is backed by valid evidence.

- Objectivity: the writing should be detached and unemotional and without direct appeal to the reader.

- Precision: anything that does not assist the argument should be omitted.

Critical and analytical thinking should be applied at all points in academic study - to selecting information, reading, writing, speaking and listening (Northedge 2005:23-43).

Here are five important proofs why critical thinking should be studied:

- Critical thinking is a domain-general thinking skill. The ability to think clearly and rationally is important whatever we choose to do. If you work in education, research, finance, management or the legal profession, then critical thinking is obviously important. But critical thinking skills are not restricted to a particular subject area. Being able to think well and solve problems systematically is an asset for any career.

- Critical thinking is very important in the new knowledge economy. The global knowledge economy is driven by information and technology. One has to be able to deal with changes quickly and effectively. The new economy places increasing demands on flexible intellectual skills, and the ability to analyse information and integrate diverse sources of knowledge in solving problems. Good critical thinking promotes such thinking skills, and is very important in the fastchanging workplace.

- Critical thinking enhances language and presentation skills. Thinking clearly and systematically can improve the way we express our ideas. In learning how to analyse the logical structure of texts, critical thinking also improves comprehension abilities.

- Critical thinking promotes creativity. To come up with a creative solution to a problem involves not just having new ideas. It must also be the case that the new ideas being generated are useful and relevant to the task at hand. Critical thinking plays a crucial role in evaluating new ideas, selecting the best ones and modifying them if necessary.

- Critical thinking is crucial for self-reflection. In order to live a meaningful life and to structure our lives accordingly, we need to justify and reflect on our values and decisions. Critical thinking provides the tools for this process of self-evaluation.

Although most people would agree that critical thinking is an important thinking skill, they also do not know how to improve their own thinking. This is because critical thinking is a meta-thinking skill. It requires careful reflection on the good principles of reasoning and making a conscious effort to internalize them and apply them in daily life. This is not easy to do and often requires a long period of training. 


\section{References:}

1. Barnett, R. (1997) Higher Education: A Critical Business. Buckingham, SRHE: Open University Press.

2. Beardsley, M. (1975) Thinking Straight. Boston: Prentice-Hall.

3. Chaffee, J. (1985) Thinking Critically. Boston: Houghton Mifflin Co.

4. Chubinski, S. (1996) Creative Critical-thinking Strategies. London: Nurse Educator.

5. DeBono, E.(1992) Teach Your Child to Think. London: Penguin.

6. Ferrett, S. (1997) Peak Performance. // Online Professional Development at http://www.ket.org/ged2002/critical/cr3.htm.

7. Klenz, S. (1987) Critical and Creative Thinking. Washington, D.C.: American Society of Association Executives.

8. Northege, A. (2005) Adult Learning. Pretoria: University of South Africa.

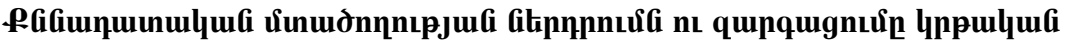

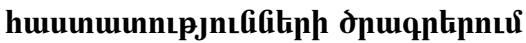

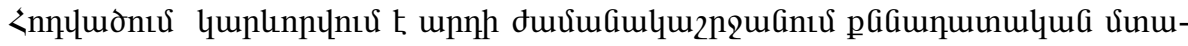

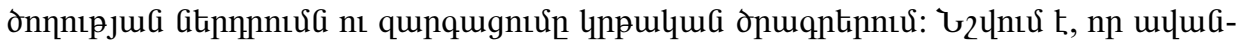

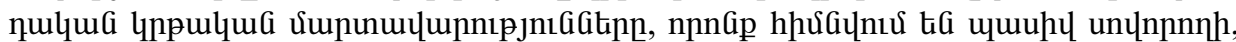

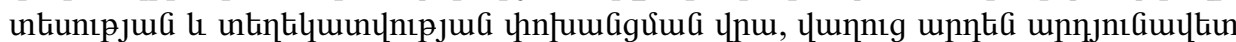

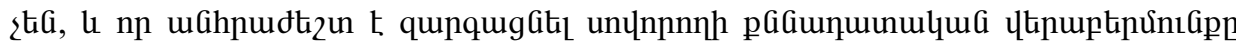

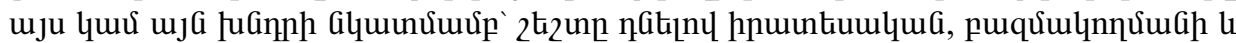

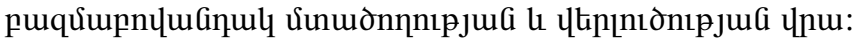

